\title{
KNOWLEDGE SHARING AND ADVICE SEEKING IN A SOFTWARE ENGINEERING COMMUNITY
}

\author{
Jie Yan and Dimitris Assimakopoulos \\ Hull University Business School and Grenoble Ecole de Management \\ j.yan@mgt.hull.ac.uk and dimitris.assimakopoulos@grenoble-em.com \\ $U K$, FRANCE
}

In this paper, we adopt a social perspective on organizational learning shedding light on advice seeking and knowledge sharing for new software development among engineers in an Internet start-up in Beijing, China. The research using recently developed computerised network analysis and visualisation techniques shows, local community of practice and participation in Chinese online technology forums, foster learning and sustain advice seeking behaviour during the engineers' complex daily work on Internet software development.

\section{INTRODUCTION}

The role of tacit knowledge in the innovation process has attracted great interest by management scholars and practitioners alike. For key application areas, such as IT, an increased understanding of the tacit nature of technical knowledge required for innovation in the production, for example, of complex software has shifted the emphasis from IT itself to the role of tacit knowledge in the innovation process, and in particular, to the study of the environment in which tacit knowledge is created and shared within or across organizational boundaries and communities of practice (Brown and Duguid, 2001; Davenport and Prusak, 1998).

This paper focuses on a start up in Beijing trying to shed light on advice seeking behaviour in the software engineering community of practice. Adopting the social perspective on organizational learning (Brown and Duguid, 1991, 1998; Nonaka and Konno, 1998; Wenger, 1998), this research assumes that knowledge, and more specifically advice, is mainly shared within the context that it is created and used for specific problem solving. In our case study of Advanced Systems Development Corporation (ASDC), software engineers make use of various social resources from within and beyond the firm boundary, such as project teams and Internet technical forums, seeking advice from colleagues, friends and members of online technical communities for learning how to solve their problems arising in new software development work. The paper is divided in four additional sections. The main concepts, including the notion of localised community of practice, are discussed in the next section. The research methodology is presented in section 3 . The main 
findings based on the ASDC case are discussed in section 4. Finally the evaluation and conclusions are drawn in section 5 .

\section{THE MAIN CONCEPTS}

The knowledge-based theory of the firm traces competitive advantages of organizations back to their capability of transforming tacit knowledge (Nonaka and Takeuchi, 1995) into unique and valuable products and services (see, also, Hamel, 1991; Grant, 1996; Spender, 1996; Teece, 1998, 2001). Tacit knowledge is highly organization-specific and invisible to outliers of the context. It is developed internally through experience-based and social complex learning processes, which involve activities and routines in individual, group and organization levels (Collis, 1991). It is embedded in the brains of individuals as well as organizational routines and cultures, and it shows low articulability, codificability and transparency (Winter, 1987). The only way to accumulate tacit knowledge is from time-consuming practice in specific organizational contexts and communities of practice.

Communities of practice have attracted considerable interest throughout the 1990s as the locus of where knowledge, and in particular tacit knowledge, is created, applied, shared, and made sense of (Lave and Wenger, 1991; Brown and Duguid, 1991; Wenger 1998). According to Wenger (1998) a community of practice refers to a group of people who share a common practice, have the need to share and exchange knowledge, and are bounded by informal relationships and a shared identity within organizational boundaries. A community of practice provides the social construct that places learning in the "context of our lived experience of participation in the world' (Wenger, 1998, p3). The common understanding of the work in hand, skill and experience, are the basis for developing a common worldview and identity for a particular organizational community of practice. This shared identity lowers the costs of communication between the community members and results in explicit and tacit rules of coordination and behaviour over time. Organizational learning is therefore viewed within this theoretical perspective as a process of participation in one or more communities of practice (Lave and Wenger, 1991; Wenger 1998).

In recent years, the widespread adoption of Internet fuelled another form of informal inter-personal support structure, virtual community. People congregate in virtual venues on the Internet to share information, knowledge, personal feeling, and other valuable resources. Rheingold (1993, p.5) termed this phenomenon: virtual community, and defined it as: "social aggregations that emerge from the Net when enough people carry on those public discussions long enough, with sufficient human feeling, to form webs of personal relationships in cyberspace". Wellman and Gulia (1997) suggest people exchanging emails or participating in a discussion forum form virtual communities providing support and sharing valuable information and knowledge with regard to specific questions surrounding a common interest. Internet forums are interest-based and operate like personal communities without propinquity (Webber, 1964) in which individuals can belong to on the basis of sharing a common interest with other fellow members over great geographical distances (see, also, Saxenian, 1999). 


\section{METHODOLOGY}

This research adopted a case study approach (Yin, 1994) and an ethnographic strategy based on social network analysis (Wasserman and Faust, 1994; Assimakopoulos, 2000) to study how knowledge is shared among software engineers in the software engineer community of practice in Advanced System Development Corporation (ASDC), in Beijing, China. ASDC was founded in 1994 as a joint venture between IBM and Tsinghua University's Department of Computer Science. Its main business is Internet software development based on Java programming language and technical support for IBM. The product development department in ASDC has five projects at the time of the fieldwork. Two of them have had 7 and 6 members each, and the remaining three teams have had 3 members each. The other two engineers are technology leaders who don't involve in development work but supervise the projects.

The study paid special attention to the advice seeking linkages within and beyond the local software engineering community. The adopted social network perspective is based on the belief that advice seeking and knowledge sharing takes place through inter-personal interaction. As it will be discussed in the following section, advice seeking is the most intensive form of social interaction, by which engineers generate and share tacit knowledge. By tracing the advice seeking linkages qualitatively and also analyzing quantitatively the structure of the advice seeking network the engineers formed within their everyday work over a considerable period of time, it is assumed that we can gain a more detailed understanding of the knowledge sharing processes within this particular software engineering community.

Participant observation took place for three and a half months in early 2002. The primary author joined the company and stayed in the development room all working hours, and several times until as late as $10 \mathrm{pm}$ when the last engineer left the workplace. The researcher had his own cubicle at the central part of the software development room, and therefore could hear and see what the engineers were talking and doing without being noticed. The researcher built good personal relationships with the engineers and frequently talked with them on research related topics over lunch or other informal occasions. Towards the end of the field study, 15 formal interviews were also carried out. A questionnaire survey was conducted to collect network data of advice seeking relations. The questionnaire contained a roster of all the software engineers and asked the respondents to indicate from whom s/he asked advice for technological problems in hand within the past months and according to what frequency. Additional questions asked information about advice seeking using personal networks and through specialised online technological forums. All the 24 engineers participated in the survey.

\section{EMPIRICAL FINDINGS}

\subsection{Software engineering community of practice}

All the software engineers in ASDC work in a big development room. Everyday the engineers spend most of their time logged on their computer. They sit in their 
cubicles, stare at the screen, click the keyboard, and check technology books. Sometimes it seems that software development is a 'person-to-machine' work. In fact, this is far from the truth. To a great extent, software development is more like a 'people-to-people' work. What engineers do is not only to deal individually with computers, but interact with their colleagues in the development room. They work collaboratively on formal project teams and also depend heavily on informal advice seeking relationships. They often talk with colleagues about technical problems in their work; and they almost daily have lunch all together, during which they talk much on various topics, jokes, sports, current affaires, as well as technology and their software development work. They share their knowledge, skills, and techniques in order to work efficiently, and they seem very happy to do so. Their shared professional experience makes them feel close to each other. More importantly, the common work practices make them have some common sense on how to deal with their software development work. According to Wenger (1998) this group of engineers can easily be characterized as a local Community of Practice (CoP).

Participant observation suggests that the advice seeking in software development room is always rather informal. Engineers generally go to their colleague's cubicle and ask a question directly. They may take a seat, or just stand by. The advice seeking discussions usually take a few minutes, or, rarely could last an hour, or more. In some cases, the discussion may attract more engineers and becomes a group discussion. The engineers may make use of a computer to design and check possible solutions. Although the engineers usually lower their voice during discussion, the people in nearby cubicles can hear them. No one complains about the on going discussions in the development room. This is the way software engineers work in ASDC CoP.

\subsection{Advice seeking network within local $\mathrm{CoP}$ of software engineers}

Figure 1 is the map of advice seeking network within ASDC. Balls represent software engineers and linkages show advice seeking relationships among engineers. The numbers near balls indicate which project team the engineer belongs to and the symbol ' $L$ ' is used to indicate that an engineer is a team leader. The positioning of engineers in Figure 1 is based on the calculation of structural equivalence among this set of actors. Wasserman and Faust (1994) define two actors in a network as structurally equivalent if they have mathematically identical connections to and from all other actors in the network. The calculation of Euclidian distances follows Equation 1 and is based on the sociometric representation of a network.

$$
\mathrm{d}_{i j}=\sqrt{\sum_{k=1}^{g}\left[\left(\mathrm{x}_{i k}-\mathrm{x}_{j k}\right)^{2}+\left(\mathrm{x}_{k j}-\mathrm{x}_{k j}\right)^{2}\right]} \quad \text { for } i \neq k, j \neq k
$$

$\mathrm{X}_{i k}$ represents the value of the tie from actor $i$ to actor $k$. If actors $i$ and $j$ are structurally equivalent, then the entries in their respective rows and columns of the sociomatrix will be identical and thus the Euclidian distance $\left(\mathrm{d}_{i j}\right)$ between them will be equal to zero. To the extent that two actors are not structurally equivalent, the 
Euclidian distance between them will be large. Euclidian distance has the properties of a distance sociomatrix, which can be computed for Equation 1 using network analysis software Ucinet (Borgatti et al., 1999). Subsequently we visualised the structural equivalence findings using a 2-dimentional scaling routine from Ucinet in conjunction with Mage (Richardson and Presley, 2001).

Figure 1 shows that members of each project team are located nearer to each other than to other colleagues within the CoP. For example, all the 7 engineers of team 1 are located in the centre and right-top part of the graph; while the 6 members of team 2 are located in the middle and lower part of the CoP.

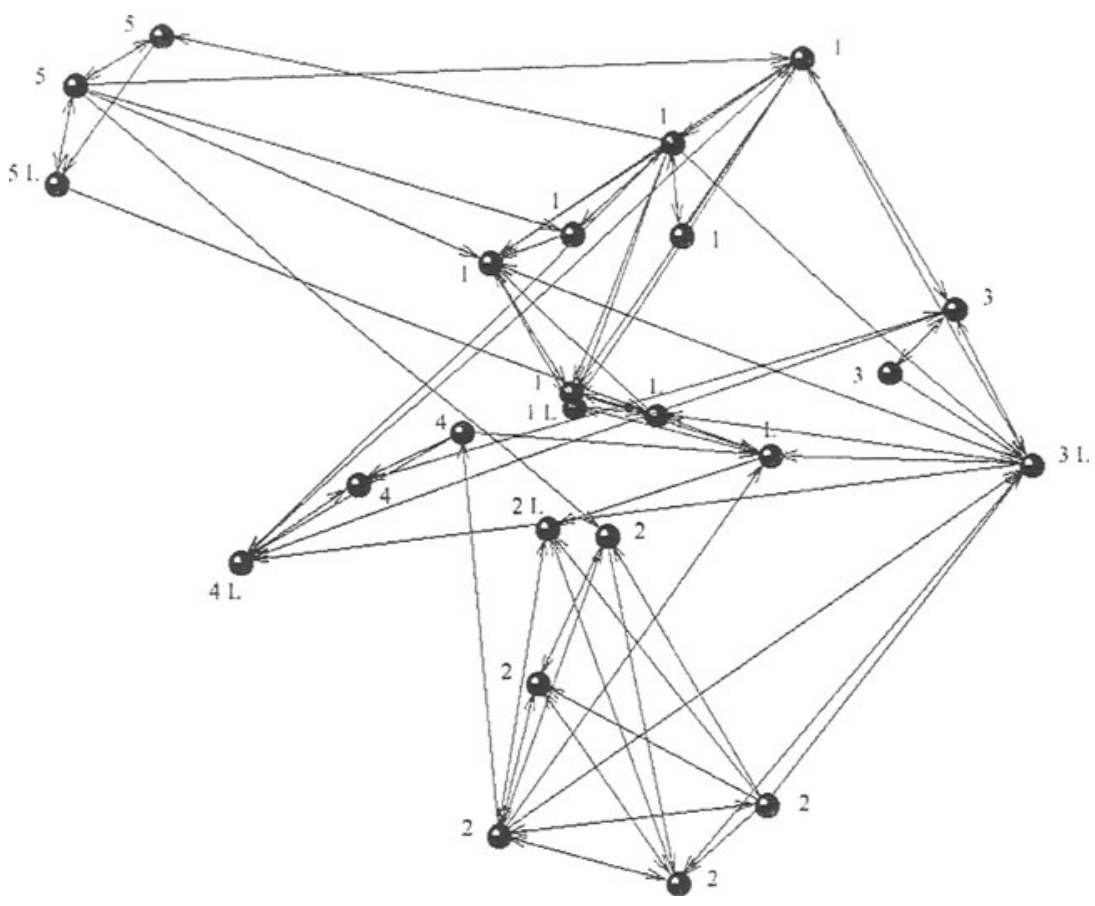

Figure 1: The advice seeking network within ASDC

The same finding applies to each and every other team within ASDC. This means that engineers belonging to the same team behave in a similar way and occupy relatively structural equivalent positions in this 2-dimensional space of advice seeking relations. According to Figure 1, the informal advice seeking behaviour of each and every project team can easily overlap with the formal boundary of the team assigned by management, highlighting the value of team working and advice seeking in complex software development work. This quantitative finding also backs up the qualitative observation that when engineers meet a technical problem, they generally prefer to discuss it with colleagues in their project team, rather than colleagues in other teams. Project team members however maintain direct linkages across their team boundary with colleagues from other teams as it can be seen in Figure 1. 
Cohesiveness or direct ties linking members of different teams can be explored by classifying advice seeking relationships into two types of linkages: strong and weak ties, according to the frequency of interactions between all possible pairs of engineers. A strong tie is defined as a linkage between two engineers when the frequency of advice seeking relationships is equal or above 5 interactions over a period of two weeks. On the other hand, a weak tie is defined as a linkage between two engineers when the frequency of interaction is less than 5 . This dichotomous distinction between strong and weak advice ties is based on the assumption that the intensity of tacit knowledge flowing between any two engineers depends on the frequency of their interaction. Table 1 shows the number of strong and weak ties within and across each and every project team in the ASDC CoP.

Table 1: Strong and weak ties within ASDC project teams

\begin{tabular}{lllll}
\hline & Strong ties & & \multicolumn{2}{c}{ Weak ties } \\
Team & Within & Across & Within & Across \\
1 & 11 & 3 & 10 & 5 \\
2 & 15 & 3 & 4 & 2 \\
3 & 5 & 5 & 0 & 4 \\
4 & 4 & 1 & 0 & 2 \\
5 & 5 & 1 & 0 & 4 \\
Sum & 40 & 13 & 14 & 17 \\
\hline
\end{tabular}

As it was expected more than three quarters of strong ties exist within project teams (40 out of 53 linkages), while less than a quarter of strong ties cross team boundary, further supporting our analysis above that most of the advice seeking happens within the boundaries of project teams. On the other hand, weak ties mainly play the role of bridge between different teams (Granovetter, 1982). More than half of the weak advice relationships cross the team boundary linking engineers across project teams.

\subsection{Advice seeking through Chinese Internet technology forums}

Besides searching information from technology web sites, ASDC engineers often seek advice and discuss their specific problems on Internet software development in Chinese online technology forums. The latter form of advice seeking and exchange is considered much more dynamic and efficient, especially, for some complex and not easily defined problems that engineers find worth discussing with colleagues outside ASDC. The messages posted daily in Chinese online technical forums usually get replies within a few hours, if not minutes. The frequency of online advice seeking is obviously lower than the advice seeking within the local CoP, which takes place about twice or three times per engineer every day.

A quarter of ASDC engineers make online enquiries more than once every day; a third make online enquiries twice or three times every week, and about 40 percent enquire once every week or less. Overall 13 percent of ASDC engineers support the statement that their development work is heavily relying on Internet technology forums, and without it, they cannot solve the everyday problems in their work 
effectively. About half suggest that the online forums are important to their work, though, they could get similar help and support from books, colleagues, and friends. And a bit more than a third thinks the online forum is not important as they can get the same help and support from other sources. It is worth also pointing out that no ASDC engineers choose the statement that online forums are not important at all and they do not use online technical forums to solve problems in their daily work.

The usual reply out of a technical forum points out what is probably wrong with a particular code of software and gives possible solutions. The senders are often professionals who have experience and knowledge of similar software problems. Most of the replies are less than 5 lines in length, but few words seem enough to help solve specific problems. Some posts which include original software code may be longer up to several pages. In some other, even longer posts, the contents are obviously copied from electronic technical documents. The senders advise to refer to the documentation for finding information about solving a particular problem. The vast majority of messages are written in mixed Chinese and English language, i.e. the software program code in English, and the diagnosis of the problem and suggestions for possible solutions in Chinese.

In some cases when the problem is rather complex, the questioning-and-replying often evolves into interactive discussions among many interested software professionals. The answer to a particular question seems more a collaborative group result. It is common after several suggestions are provided by different respondents; the engineer who initially asked the question tests these alternatives, and reports back to the forum the input and output, compiler message, and mistake information. In this way, more and more contextual information is provided and the online discussion goes deeper and deeper. Although most of the online discussions are completed within 10 exchanges, it is not infrequent to see some enquiries getting back 30 or more replies. Sometimes this interactive discussion would last a few hours, even one or two days. Rarely, questions cannot get a solution after several rounds of exchanges. However what it never happens is that an enquiry get no reply.

Based on the questionnaire survey, all 24 engineers listed up two technical forums from which they often seek advice. Totally 14 forums were suggested, including China Software Developer Net http://www.CSDN.net ; China Java Sun forum http://www.java.sun.com.cn ; Tsinghua University BBS http://bbs.tsinghua.edu.cn and others. Among them, CSDN is the most popular technical forum, listed by 9 out of the 24 software engineers in ASDC. CSDN is one of the biggest Chinese software technology forums. Every day about 80,000 people visit the forum with unique IP address, and deliver more than 1,500,000 page views (CSDN, 2002). Most of them are professional software developers in IT firms all over China. There are always 2,000 to 3,000 software developers online in the forum during working hours (see name list of online members, http://expert.csdn.net/expert/forum.asp). Every day hundreds of technical problems are posted and discussed. The huge number of online members ensures the critical mass (Oliver et al., 1985) and diversity of technical backgrounds of the participants on ongoing discussions. 


\section{EVALUATION AND CONCLUSIONS}

In the software engineering CoP in ASDC, most of the advice seeking happens among the project team colleagues as it was discussed in 4.2. Based on our questionnaire survey, 22 out of 24 engineers choose the statement that team colleagues know each other's work tasks, and thus can easily understand the specific context and problem in hand. Problems in software development are not only related to the generic language programming techniques, but they are also closely associated with specific domain knowledge and project techniques embedded in the system design. Each part of a complex system may have many visible or hidden relations with other parts that are easier to understand within project teams. Colleagues from the same project team certainly know more about such tacit knowledge than colleagues outside project team. When discussing a problem with colleagues outside a project team, additional effort has to be made to explain the context specific tacit knowledge related to a problem.

The division into project teams makes to a certain extent the local CoP discontinuous. Each project team has its sub-context and tasks related to specific domain knowledge and computer techniques applied. However it does not seem appropriate to locate $\mathrm{CoP}$ at team level. Project team is only a temporary organizational arrangement and this is reflected in the response of only a quarter of engineers who think that team colleagues have the entire responsibility to solve problems within a particular project. When a project is finished, or a new project starts, the same engineers who are part of one team would be instantly re-organized in new project teams. More importantly, all the engineers in the development room of ASDC do visibly form a single community. They work together over a long period of time, interact with each other, and pursuit a common enterprise. The advice seeking network (Figure 1) also reveals that all engineers are directly or indirectly connected with regard to advise seeking relationships. Although project team has its specific content, meaning and tacit knowledge, it is inextricably embedded in the whole CoP.

In Wenger's theoretical framework (1998) however a CoP is an amorphous, fairly closed and self-evolving group of people bounded by strong interactive work (or other) relationships. Members are closely connected but they have few external knowledge linkages. This is probably true, for example, with respect to claim processors (Wenger, 1998), copier sales people (Østerlund, 1996), photocopier repairmen (Brown and Duguid, 1991), midwifes, butchers, tailors, and so on (Lave and Wenger, 1991). In such organizational settings, the knowledge base of CoPs is relatively simple and stable, and therefore lacking of need for intensive external knowledge transfer and sharing. This however is not directly applicable to the software engineering community of ASDC, which is an organization engaging in complex technological and fast moving innovation directly related to the Internet.

We argue that the CoP at ASDC provides a detailed and refined model of technical communities of practice in IT related industries. The ASDC software engineers rely on their local $\mathrm{CoP}$ for tacit knowledge sharing but also they make effective use of their external linkages to Internet technical forums to get useful support and additional advice for their everyday work. In this sense there is a 3-step process in which engineers prefer to discuss their technical problems with local 
community members first, but when they fail to find solutions within project team (step 1) and local CoP (step 2), then they immediately turn to the online technical forums (step 3) to seek further advice and support. Each one of these steps requires extra effort to communicate and share relevant tacit knowledge within or across organizational boundaries. One could therefore argue that this model of advice seeking is a valuable addition to the existing literature in terms of how Internet related CoPs solve problems faster, using multiple memberships and external linkages for sustaining, sharing and transferring tacit knowledge completely new to the local CoP.

Therefore the ASDC case illustrates how Chinese software engineers make effective use of complementary social resources within a broader spectrum of choices compared to traditional CoPs, for seeking advice, learning how to solve problems, and transfer knowledge to the local $\mathrm{CoP}$ from far beyond the firm boundary. One limitation to these findings may be the "unusual" large number of software professionals participating in Chinese online technology forums. For example, CSDN has 200,000 members, 80,000 visit daily, and 2,000 - 3,000 software developers keep online during working hours (CSDN, 2002). This deserves further research in other countries and organizational settings.

\section{REFERENCES}

Assimakopoulos, D.G., (2000), Social network analysis as a tool for understanding the diffusion of GIS innovations, Environment and Planning B, 27, pp.627-640.

Borgatti, S.P., Everett, M.G. and Freeman, L.C., (1999), UCINET 5.0, Columbia, Analytic Technologies.

Brown, J.S. and Duguid, P., (1991), Organizational learning and communities of practice: towards a unified view of working, learning and innovation, Organization Science, 2 (1), pp.40-57.

Brown, J.S. and Duguid, P., (1998), Organizing Knowledge, California Management Review, 40 (3), pp.90-112.

Brown, J.S. and Duguid, P., (2001), Structure and spontaneity: knowledge and organization, in Nonaka, I. and Teece, D.J. (Eds.), Managing Industrial Knowledge: Creation, Transfer and Utilisation, London: SAGE Publication.

Collis, D.J., (1991), How valuable are organizational capabilities? Strategic Management Journal, 15, pp.143-52.

CSDN, (2002), Introduction pages of CSDN, Received on Dec 1st, 2002 from World Wide Web http://www.csdn.net/intro/intro.asp?id=8.

Davenport, T.H. and Prusak L, (1998), Working Knowledge: How Organizations Manage What They Know, Cambridge, MA: Harvard Business School Press.

Granovetter, M., (1982), The Strength of Weak Ties: A Network Theory Revisited, in Marsden, P. V. and Lin, N. (Eds.) Social Structure and Network Analysis, pp.105-130, Beverly Hills, CA: Sage.

Grant, R.M., (1996), Prospering in dynamically-competitive environments: organizational capability as knowledge integration, Organization Science, 7, pp.375-87.

Hamel, G., (1991), Competition for Competence and Interpartner Learning within International Alliances, Strategic Management Journal, 12, (Special issue), pp.83-103.

Lave, J. and Wenger, E. (1991), Situated Learning: Legitimate Peripheral Participation, Cambridge: Cambridge University Press.

Leonard-Barton, D., (1992), Core capabilities and core rigidities: A paradox in managing new product development, Strategic Management Journal, 13, pp.111-125.

Nonaka, I. and Konno, N., (1998), The concept of 'Ba': Building a Foundation for Knowledge Creation, California Management Review, 40 (3), pp.40-54.

Nonaka, I. and Takeuchi, H., (1995), The Knowledge Creating Company, Oxford: Oxford University Press.

Oliver, P., Marwell, G. and Teixeira, R., (1985), A theory of critical mass: I. interdependence, group heterogeneity, and the production of collective action, American Journal of Sociology, 91 (3), pp.522556. 
Østerlund, C., (1996), Learning Across Contexts: A Field Study of Salespeople's Learning at Work, Skriftserie for Psykologisk Institute, 21 (1), Aarhus, Denmark: Aarhus University, Psykologisk Institute.

Rheingold, H., (1993), The Virtual Community: Homesteading on the Electronic Frontier, Menlo Park, CA: Addison-Wesley.

Richardson, D and Presley, B, (2001), MAGE 5.8, Biochemistry Department, Duke University, Durham NC.

Saxenian, A., (1999), The Silicon Valley-Hsinchu connection: technical communities and industrial upgrading, Received on Nov $19^{\text {th }}, 2000$, from http://www.geo.ntnu.edu.tw/faculty/jinnyuh

Spender, J., (1996), Making knowledge the basis of a dynamic theory of the firm, Strategic Management Journal, 17, pp.45-62.

Teece, D.J., (1998), Capturing Value from Knowledge Assets: The New Economy, Markets for Knowhow, and Intangible Assets, California Management Review, 40 (3), pp.55-79.

Teece, D.J., (2001), Strategies for Managing Knowledge Assets: the Role of Firm Structure and Industrial Context, in Nonaka, I., and Teece, D, (Eds.), Managing Industrial Knowledge, London: SAGE Publication.

Wasserman, S. and Faust, K., (1994), Social Network Analysis: Methods and Application, Cambridge University Press.

Webber, M., M., (1964), The Urban Place and the Non-Place Urban Realm, in Webber, M., M., et al. (Eds.) Exploration into Urban Structure, pp.79-153, Philadelphia, PA: University of Pennsylvania Press.

Wellman, B. and Gulia, M., (1997), Net Surfers Don't Ride Alone: Virtual Community as Community, in Kollock, P. and Smith, M., (Eds.) Communities in Cyberspace, Berkeley, CA., University of California Press

Wenger, E., (1998), Communities of Practice: Learning, Meaning, and Identity, Cambridge: Cambridge University Press.

Winter, S.G., (1987), Knowledge and Competence as Strategic Assets, in Teece, D.J. (ed.) The Competitive Challenge: Strategies for Industrial Innovation and Renewal, Cambridge, MA: Ballinger.

Yin, R K, (1994), Case Study Research, Thousand Oaks, CA: Sage. 